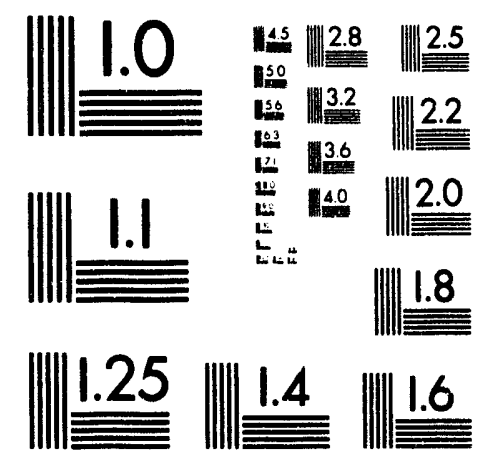



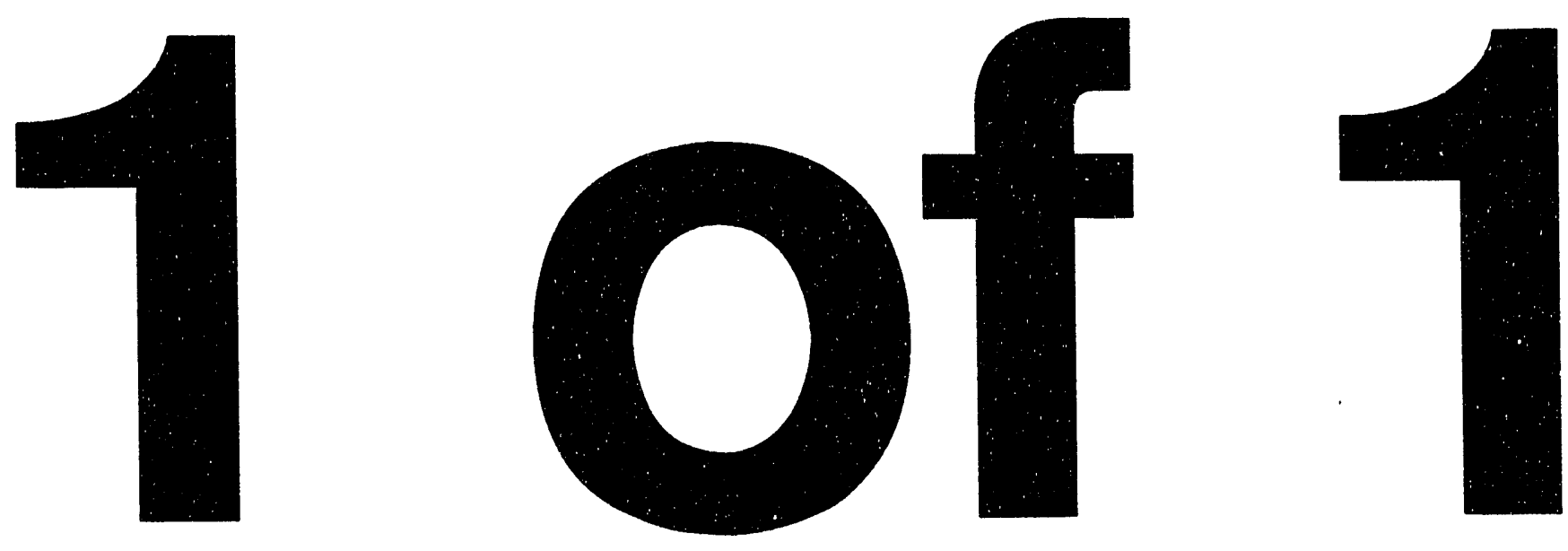
CCRL- ID. 114054

PREPRINT

\title{
INCLUSION OF A THREE-DIMENSIONAL WASHOUT COEFFICIENT IN ADPIC
}

\author{
Erik Näslund and Hans Homström \\ National Defence Research Establishment \\ FOA 4 \\ S-901 82 Umeå, Sweden
}

May 1993

This is a preprint of a paper intended for publication in a journal or proceedings. Since changes may be made before publication, this preprint is made available with the understanding that it will not be cited or reproduced without the permission of the author. 


\section{DISCLAIMER}

This document was prepared as an account of work sponsored by an agency of the United States Government. Neither the United States Government nor the University of California nor any of their employees, makes any warranty, express or implied, or assumes any legal liability or responsibility for the accuracy, completeness, or usefulness of any information, apparatus, product, or process disclosed, or represents that its use would not infringe privately owned rights. Reference herein to any specific commercial products, process, or service by trade name, trademark, manufacturer, or otherwise, does not necessarily constitute or imply its endorsement, recommendation, or favoring by the United States Government or the University of California. The views and opinions of authors expressed herein do not necessarily state or reflect those of the United States Government or the University of California, and shall not be used for advertising or product endorsement purposes.

This report has been reproduced directly from the best available copy.

Available to DOE and DOE contractors from the

Office of Scientific and Technical Information

P.O. Box 62, Oak Ridge, TN 37831

Prices Available from (615) 576-8401

Available to the public from the

National Technical Information Service

U.S. Department of Commerce

5285 Port Royal Road

Springfield, VA 22161 


\title{
INCLUSION OF A THREE-DIMENSIONAL WASHOUT COEFFICIENT IN ADPIC
}

\author{
ERIK NÄSLUND ${ }^{1}$ and HANS HOLMSTRÖM ${ }^{1}$ \\ Physical Sciences Department. Regional Atmospheric Sciences Division. \\ Lawrence Livermore National Laboratory, Livermore, CA 94550, U.S.A.
}

\begin{abstract}
In ADPIC, the deposition emerging from washout has thus far been modelled rather crudely, since the only option has been to turn the rain on and off at different times. This kind of modelling is particularly unsatisfactory when ADPIC is used to model continous releases over long periods of time. The assumption of simultaneous rain throughout such a large plume is simply not true.

In this report a modified version of ADPIC with a three-dimensional (3-D) washout coefficient is presented. The effect of space variable precipitation is examined via two separate releases that are simulated for a period of 48 hours; one continous 'Chernobyl-like source' release and one instantaneous 'nuclear explosionlike'. Simulations with both the new and old formulation are made and the resulting deposition patterns are compared.
\end{abstract}

'Permanent adress: National Defence Research Establishment. S-901 82 Umeå. Sweden 


\section{Introduction}

The last decade the MEDIC/MATHEW/ADPIC codes have been used in a number of different research projects at National Defence Research Establishment (FOA), Umeå, Sweden. These projects have been devoted to enhance the knowledge of dispersion and diffusion processes in the atmosphere of toxic and/or radioactive material. Since the damages from the Chernobyl accident were rather severe in Sweden, much attention has been paid to the problem of long-range transport of such materials.

When applied to a large scale, one of the major shortcomings of ADPIC has always been the very crude way it handles washout; the only option is to turn precipitation on or off throughout the domain simultaneously. This is partly due to ADPIC originally being created for calculating dispersion over limited regions and, until now, limited amount of precipitation data being available from various weather forecast centers. However, better observations and improved forecast models will eventually provide most of the information necessary to produce a good washout modeling. For instance, today it is possible to obtain 3-D rainrate fields from the European Centre for Medium-Range Weather Forecasts (ECMWF). ECMWF is also the the main source of meteorological data for our model efforts in Sweden.

Thus, in this report we present a version of MEDIC/ADPIC that reads the observed and/or forecasted precipitation field, interpolates it to the ADPIC grid, and translates rainrate to a washout coefficient at the actual particle position. Using the meteorological scenario that existed from 9008250000 to 9008270000 (i.e. $48 \mathrm{~h}$ ), the results from the new version is compared to those of the old version in simulated releases originating from the Norwegian west coast (Bergen).

\section{Reading and preprocessing the rainrate array}

There are numerous possibilities on how to receive and process the data to make it accessible to the washout calculations in ADPIC. Since the data from ECMWF consists of observation/forecast records at a number of predefined positions and heights and we already have an interface that creates the input files to MEDIC, we simply add the arrays to the UPR-records in WINDY.DAT (see appendix A for a sample of the WINDY-file). The array is then read and interpolated to the MEDIC grid. Since we do not intend to do anything with the rainrate array in MATHEW, the array is transformed to the ADPIC-grid and written to an unformatted file called PREC.nnn. This file does not contain any IDBLOCK, but is otherwise similar to the MVEL.nnn-files that MEDIC produces as input to MATHEW. The necessary changes to MEDIC with a listing of some of the coding can be found in Appendix B. 
This scheme completely overrides the old scheme where an array of times told you when to change the washout coefficient throughout the domain.

\section{Performing the washout in ADPIC}

ADPIC reads the PREC.nnn-files after the velocity fields are read. In the code stream the call to VELBAR is immediately followed by a call to a new subroutine, READPREC. The existing rainrate array has to be translated to a washout coefficient. This translation is made according to Crandall et al.. 1973, where the was'hout coefficient is shown to be dependent on both particle radius and rainrate. A reasonably well-fitting polynomial function for the measured curves over the whole spectrum of particle radii and rainrates can be written as

$$
\begin{array}{lr}
f(q)=a_{1} q+a_{2} q^{2} & r<0.5 \mu m \\
\Lambda_{1}(r, q)=0.0, & r<10.0 \mu m \\
\Lambda_{1}(r, q)=\left(b_{0}+b_{1} r+b_{2} r^{2}+b_{3} r^{3}\right) f(q), & 0.5 \mu m<r<10 \\
\Lambda_{1}(r, q)=f(q), & r>10.0 \mu m
\end{array}
$$

where $q$ is the rainrate, $r$ is the particle radius and $\Lambda_{l}$ is the washout coefficient. The coefficients, $a_{n}$ and $b_{n}$, are given in Appendix C. If, however, the particle is within a cloud, it serves as a condensation nucleus and small particles are also subjected to rainout. This shows that the effect of decreasing washout coefficient with decreasing radius is gone and the rainout can be described by

$$
\Lambda_{2}(r, q)=f(q),
$$


where $\Lambda_{2}$ is the rainout coefficient and $f(q)$ is described by Eq. (1a). For particle radii larger than $10 \mu \mathrm{m}$, the rainout and washout coefficients are equal. In Fig. 1 the function described by Eqs. (1a-d) is shown.

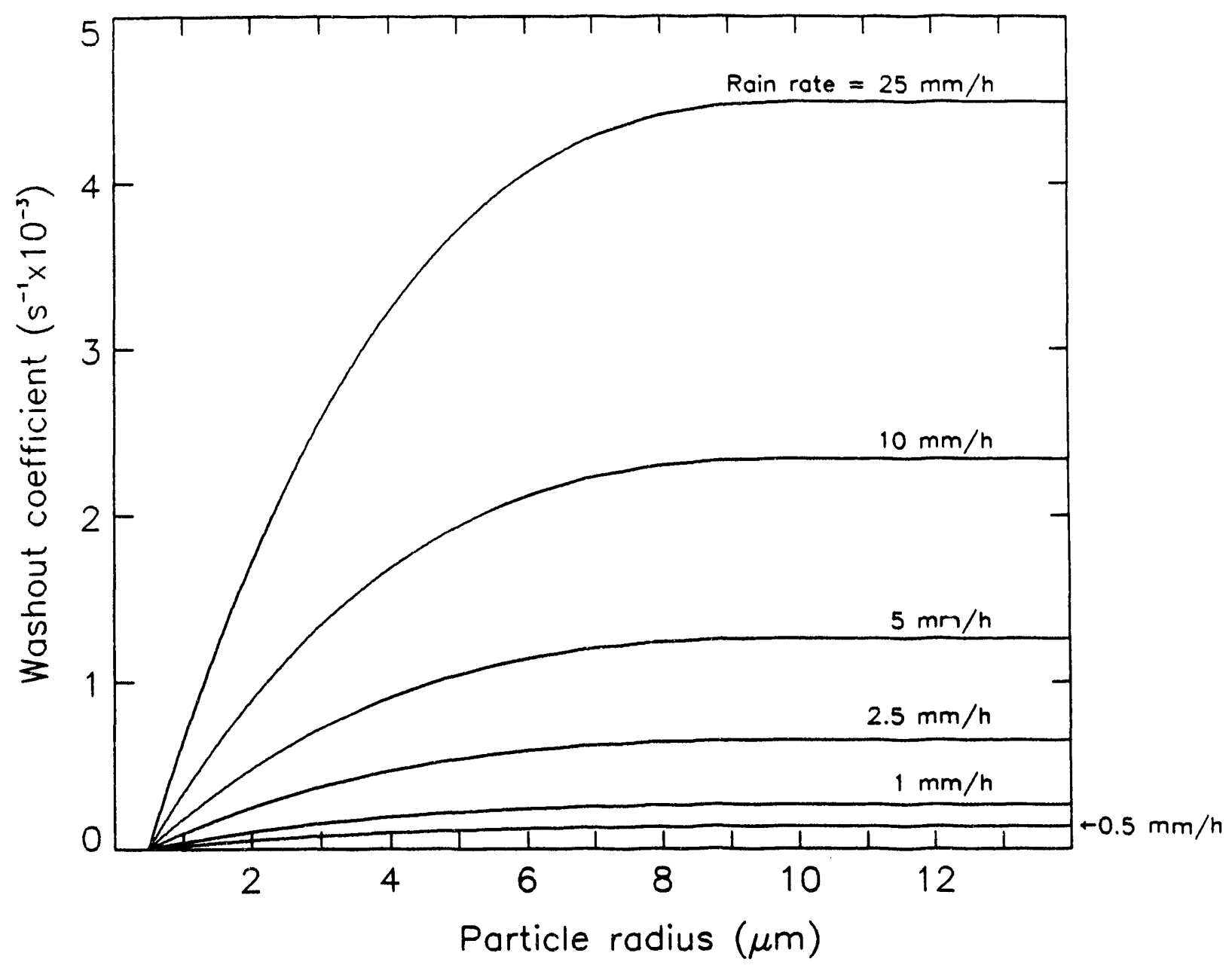

Figure 1. The washout coefficient as described by Eqs. (1a-d).

The results in this paper are derived from the assumption that the particles are subjected to washout (Eq. 1). However, in order to estimate the importance of rainout, in some runs a 'cloudflag' is added. First, to determine if the particle is within a cloud or not, the rainrate at the particle position is compared to the rainrate at the node above the particle. Second, if there is a substantial difference between the rates, the particle is subjected to in-cloud rainout and Eq. 2 will apply. The coding sequences that describe Eqs. (1) and (2) can be found in Appendix C. 


\section{Two test cases: releases over Scandinavia.}

To compare the new feature of ADPIC with that of the old version, two test simulations have been made. One case is an instantaneous release with a source term similar to a $5 \mathrm{kt}$ nuclear explosion, the other is a continous release, Chernobyl-like source. Both cases use the same weather scenario; weather data recieved from ECMWF for the period 9008250000 (release start) to 9008270000.

This scenario is characterized by a low-pressure system with associated precipitation that travels from west to east during the simulation period. In Fig. 2 the rainrate at ground level is shown at four different times. To appreciate the 3-D nature of the rainrate field, the field at a height of $2500 \mathrm{~m}$ is shown in Fig. 3. Above $3000 \mathrm{~m}$ there is actually no precipitation at all.

The old washout model consisted of an option to turn precipitation on and off at different times. Our modeling of washout, using the old scheme, consisted simply of a careful study of particle positions versus precipitation to be able to turn it on when we considered the cloud of particles to be affected. Our study concluded that a washout coefficient of strength 0.0001 should be turned on between 9008251500 and 9008260100 , at other times it should be turned off. This method relied upon performing a test run without precipitation in order to see where the particles are at different times. It is of course possible to do this in an iterative manner; i.e. changing the times and values of washout to make a 'best fit' to known data. This is, however, highly artificial and the results that are presented here stem from one single study of particle positions and precipitation field..

In Figs. 4-6 a comparison between the two models is made at 24, 36, and 48 hours after

start of release, respectively. These figures show ground deposition from the instantaneous release.

In Figs. 7-9 a similar comparison is made for the continous release.

Finally, in Figs. 10 and 11 a comparison between pure washout and washout/rainout is shown. 

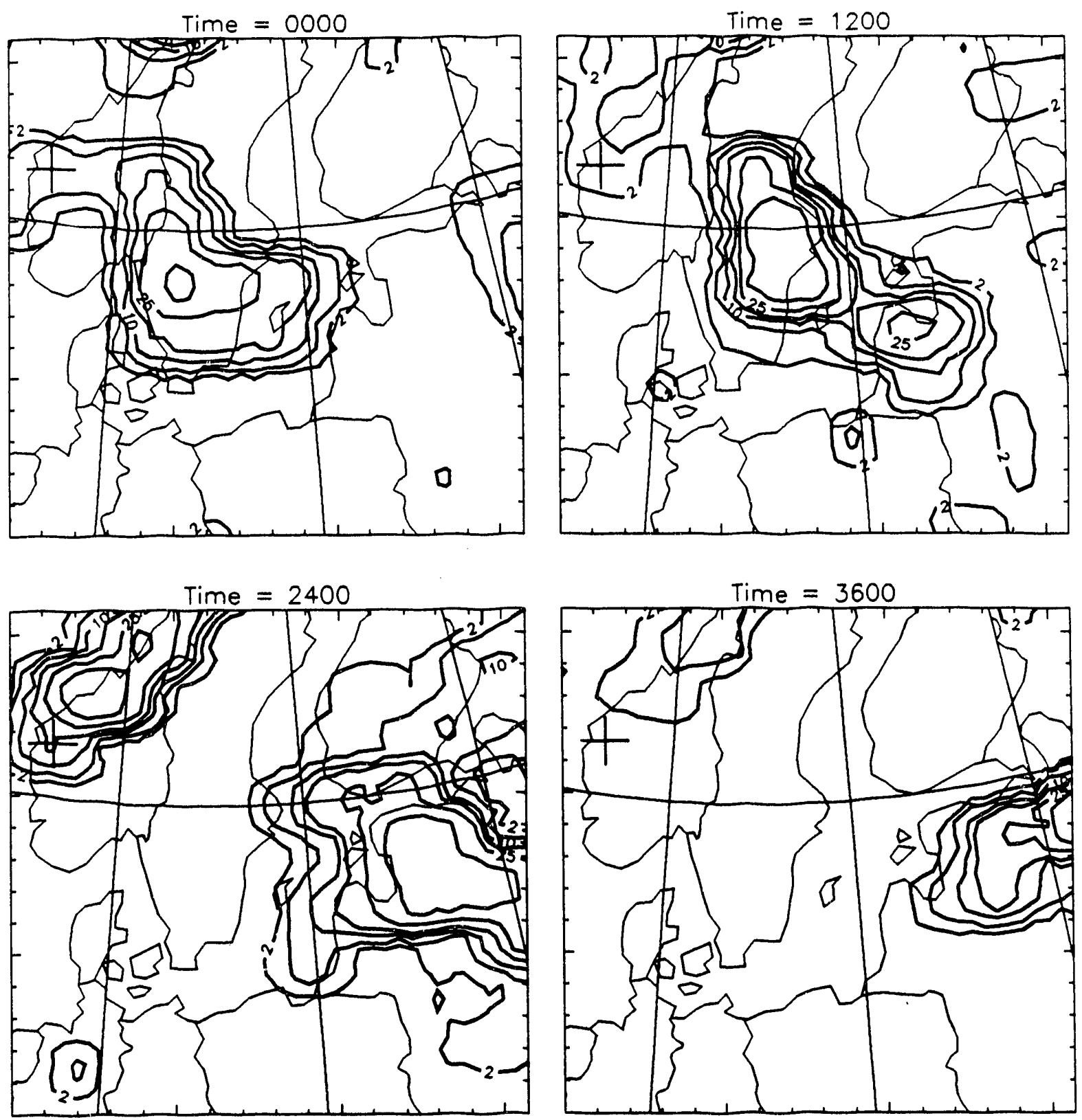

Figure 2. The precipitation field at ground at four different times. The contours indicate a rainrate of $2,5,10,25$, and $40 \mathrm{~mm} / \mathrm{h}$. The + sign indicates the release point. 

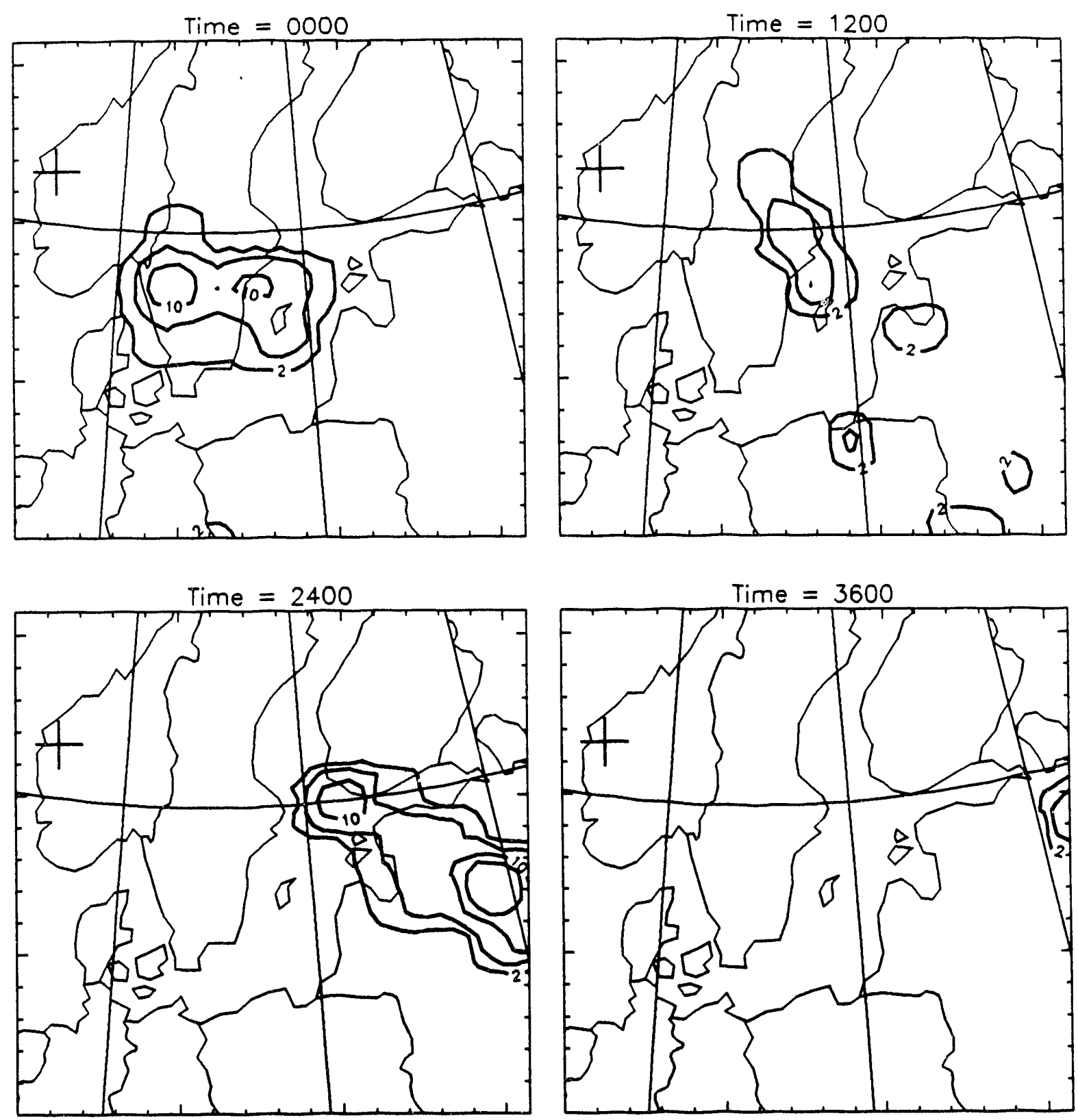

Figure 3. The precipitation field at a height of $2500 \mathrm{~m}$ at four different times. The contours indicate a rainrate of $2,5,10,25$, and $40 \mathrm{~mm} / \mathrm{h}$. The + sign indicates the release point. 
"NEW" MODEL

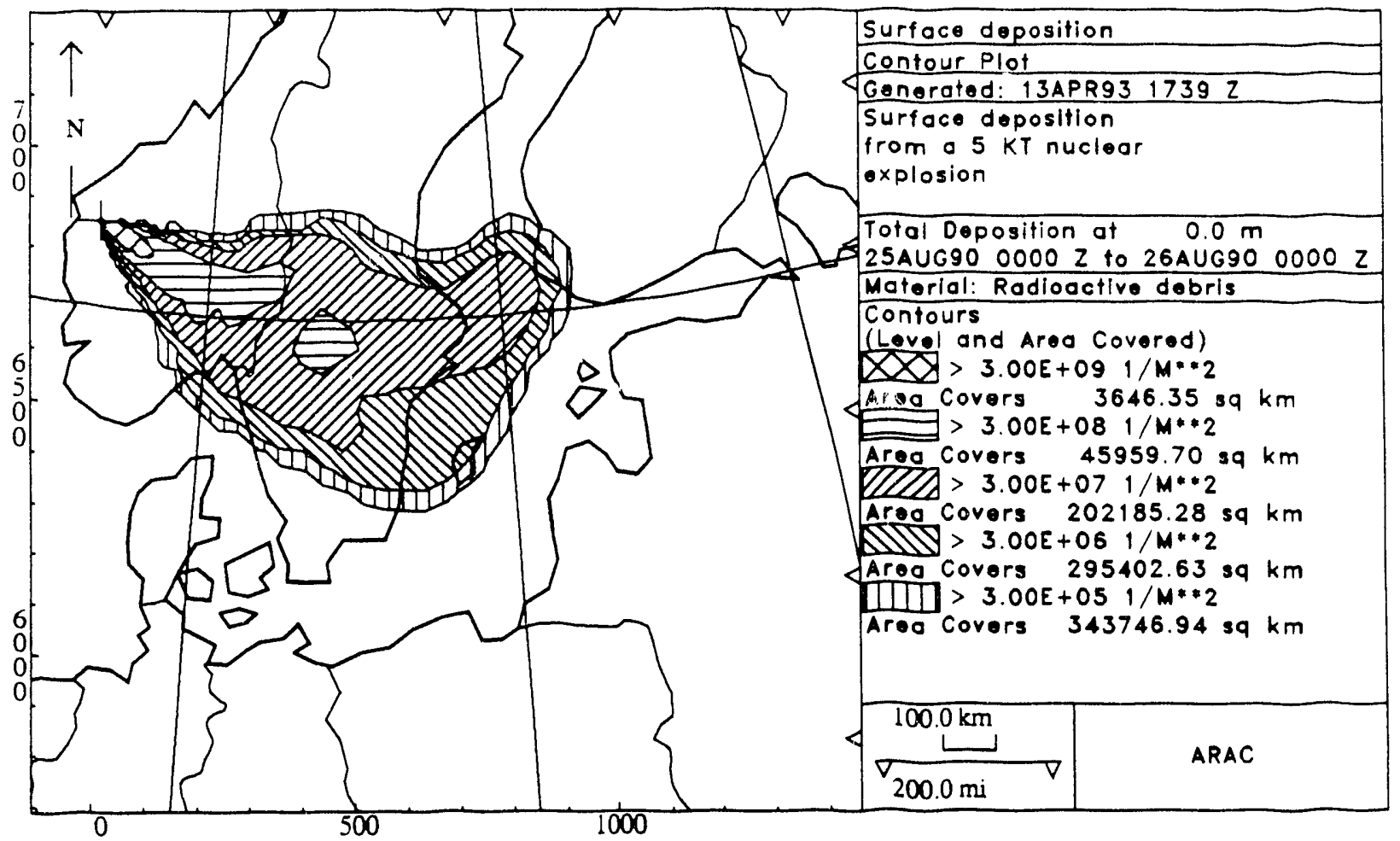

"OLD" MODEL

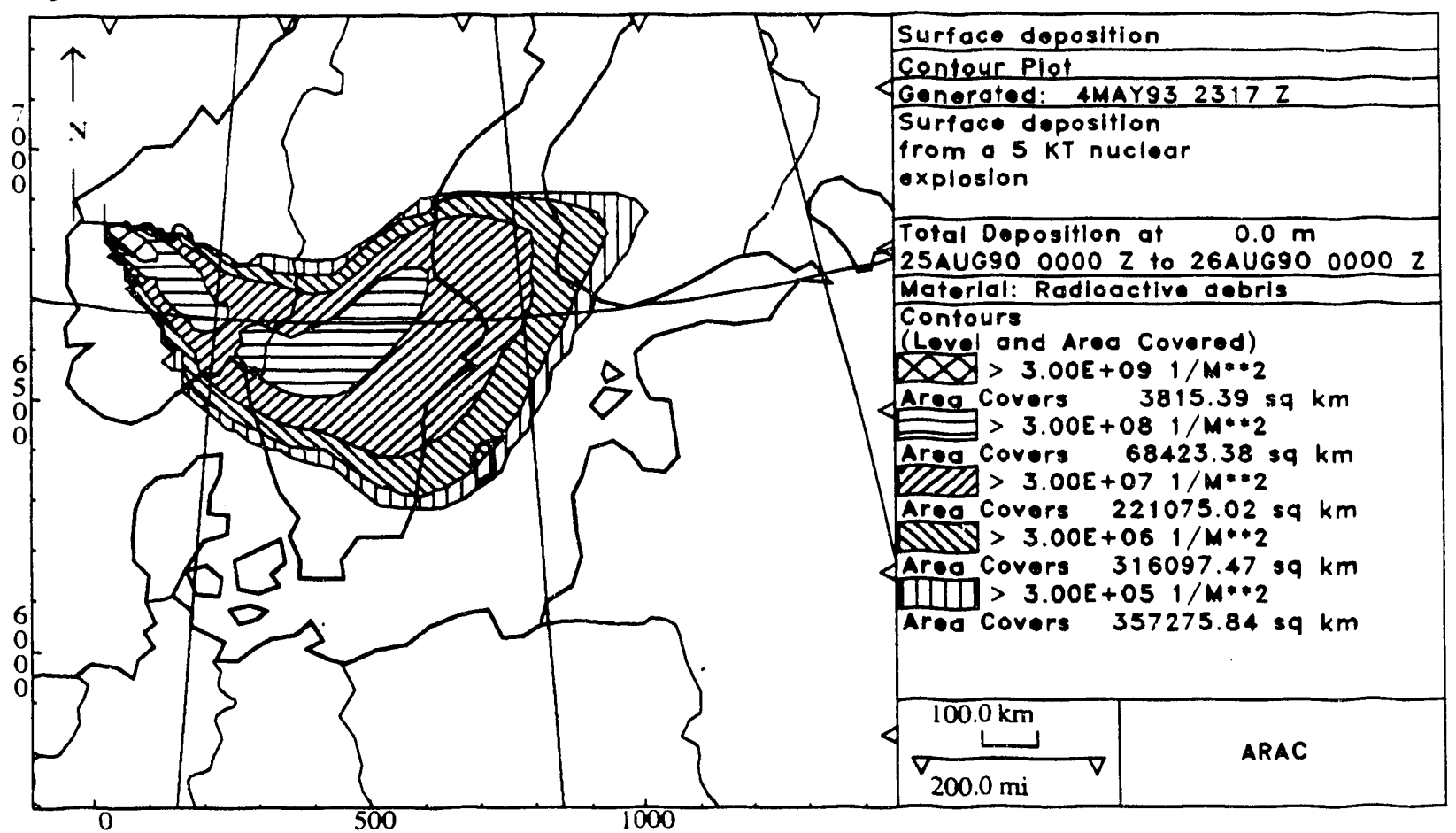

Figure 4. Instantaneous release. Ground deposition $24 \mathrm{~h}$ after the release. 
"NEW" MODEL

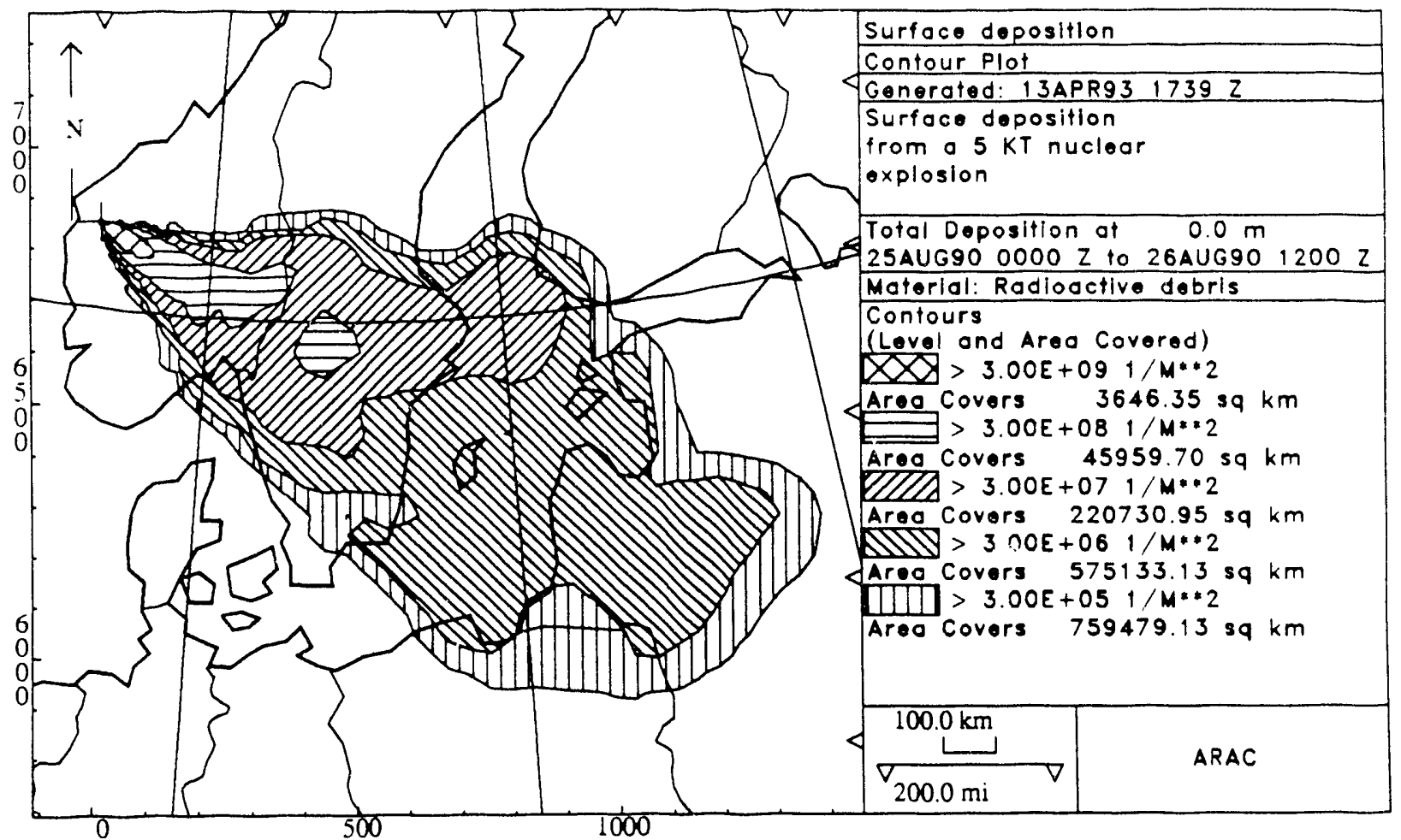

\section{"OLD" MODEL}

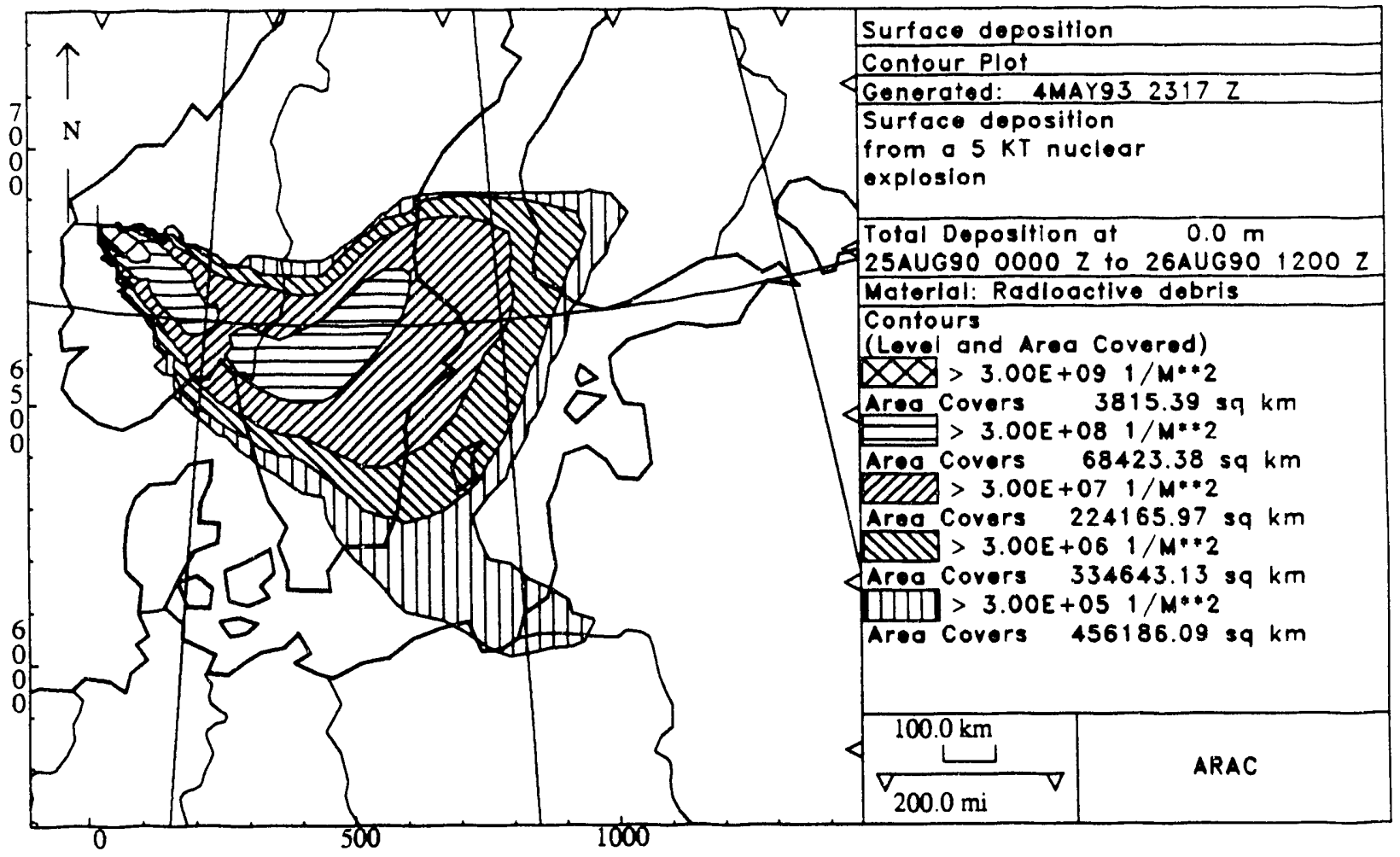

Figure 5. Instantaneous release. Ground deposition $36 \mathrm{~h}$ after the release. 
"NEW" MODEL

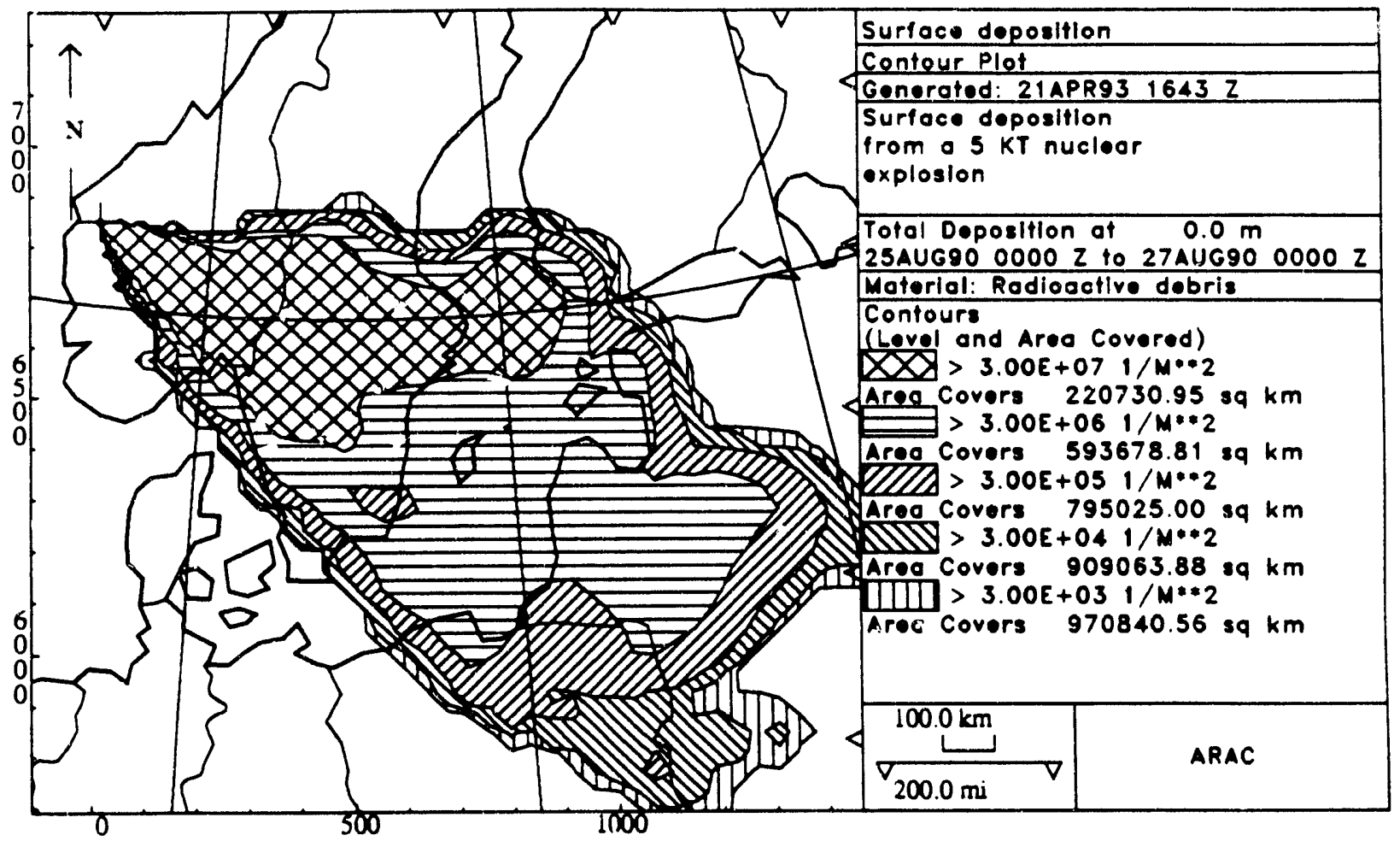

\section{"OLD" MODEL}

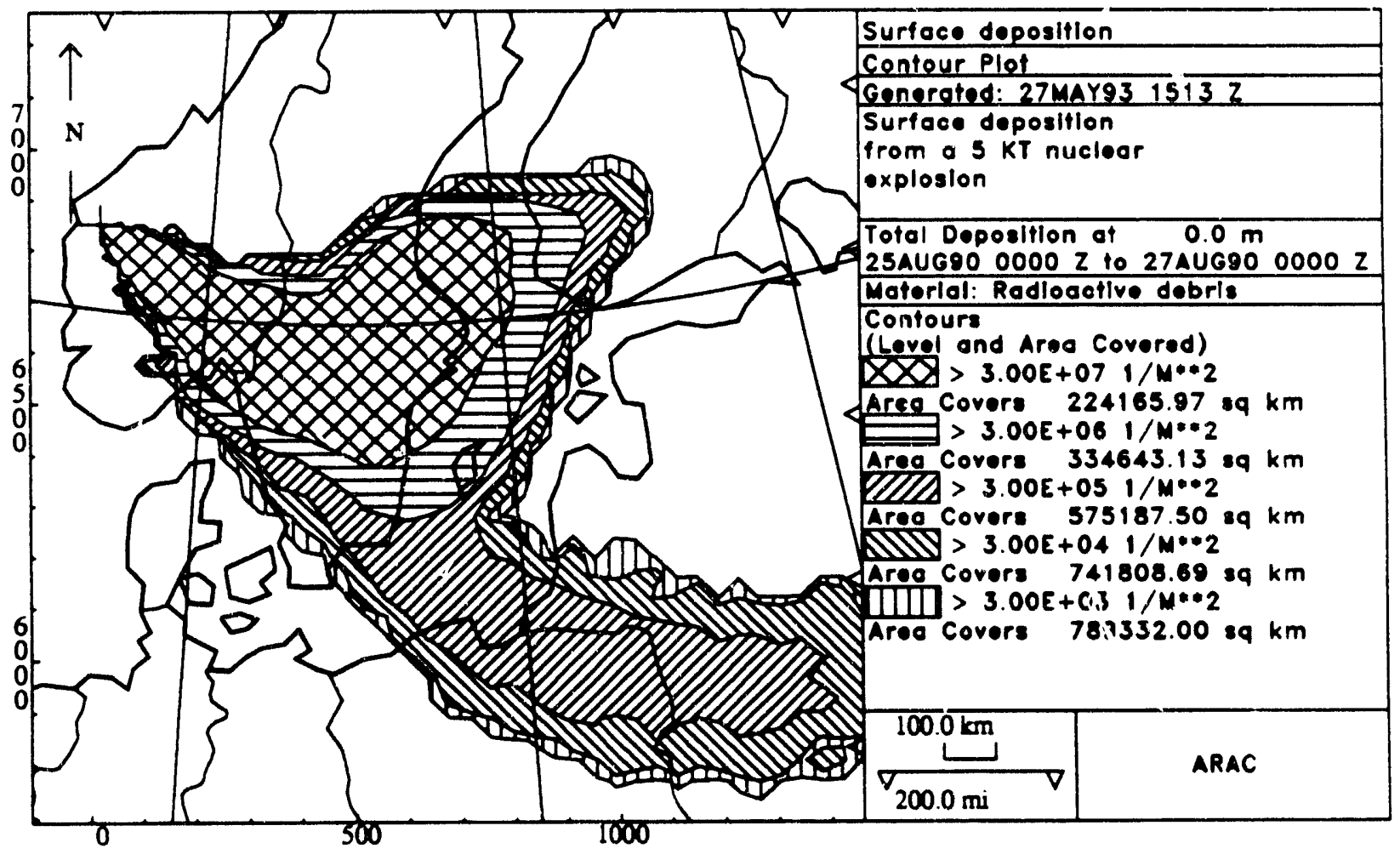

Figure 6. Instantaneous release. Ground deposition $48 \mathrm{~h}$ after the release. Observe that the contour levels differ from those in Figs. 4 and 5 in order to better resolve the deposition field far from the source. 
"NEW" MODEL

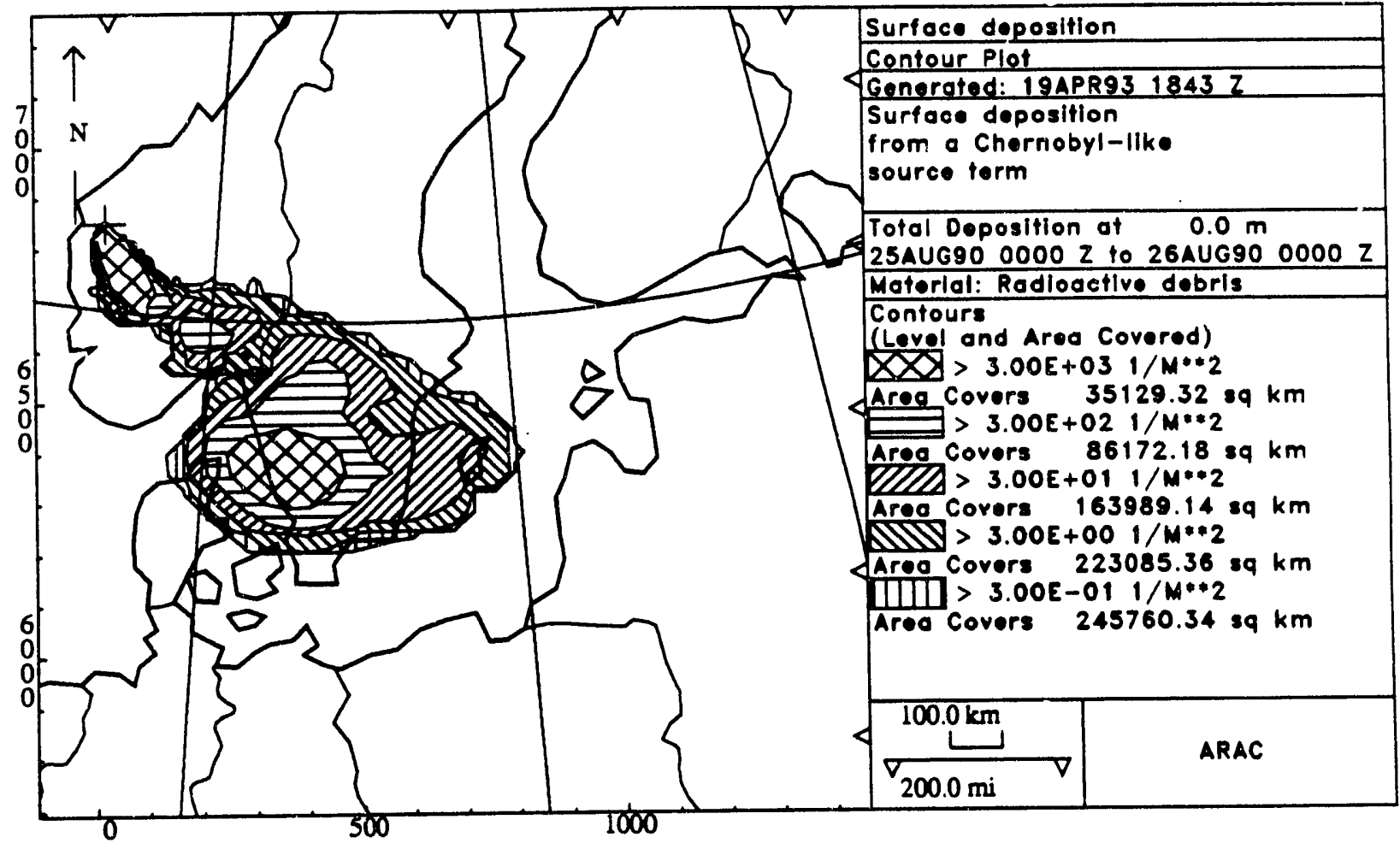

"OLD" MODEL

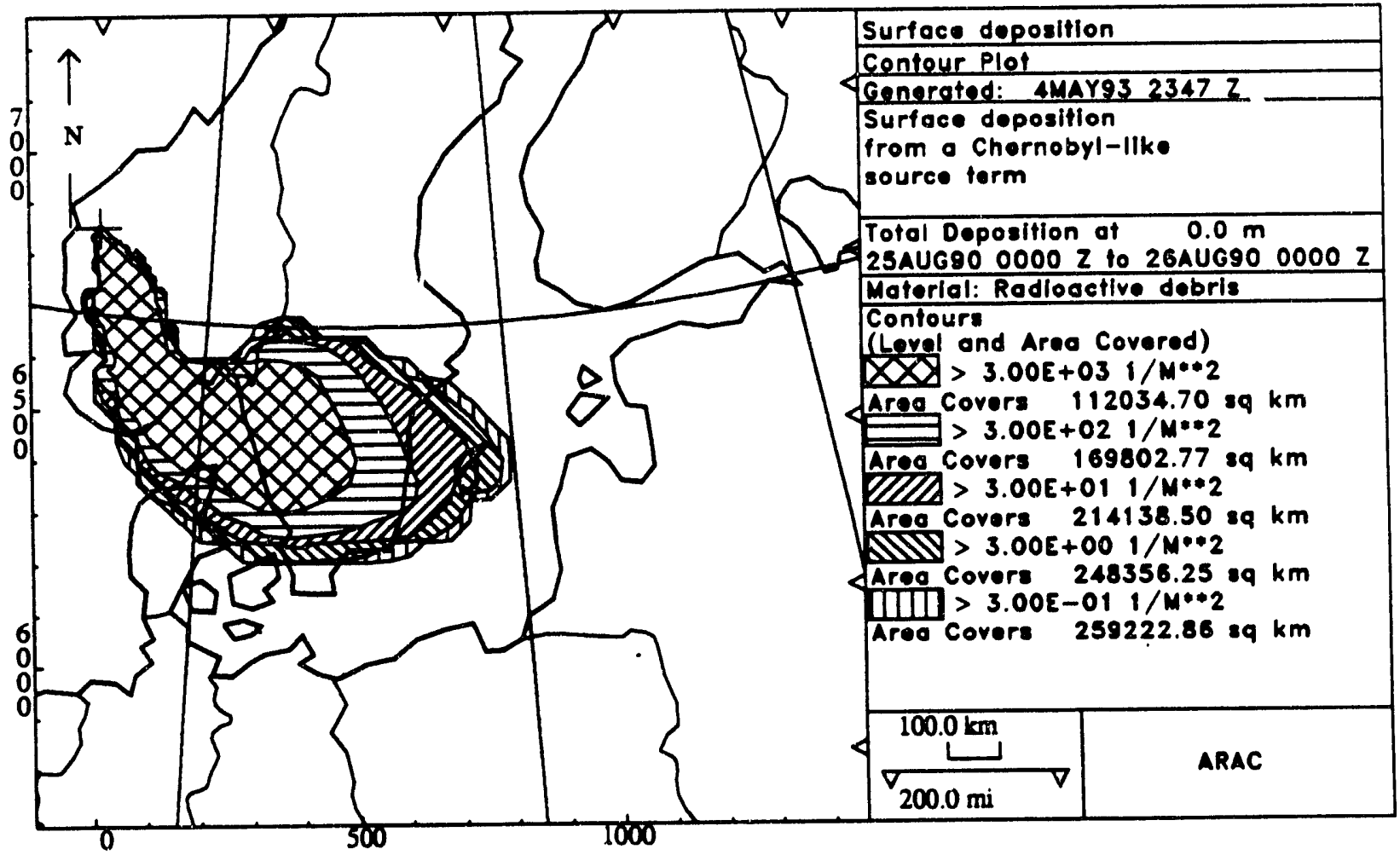

Figure 7. Continuous release. Ground deposition $24 \mathrm{~h}$ after start of release. 
"NEW" MODEL

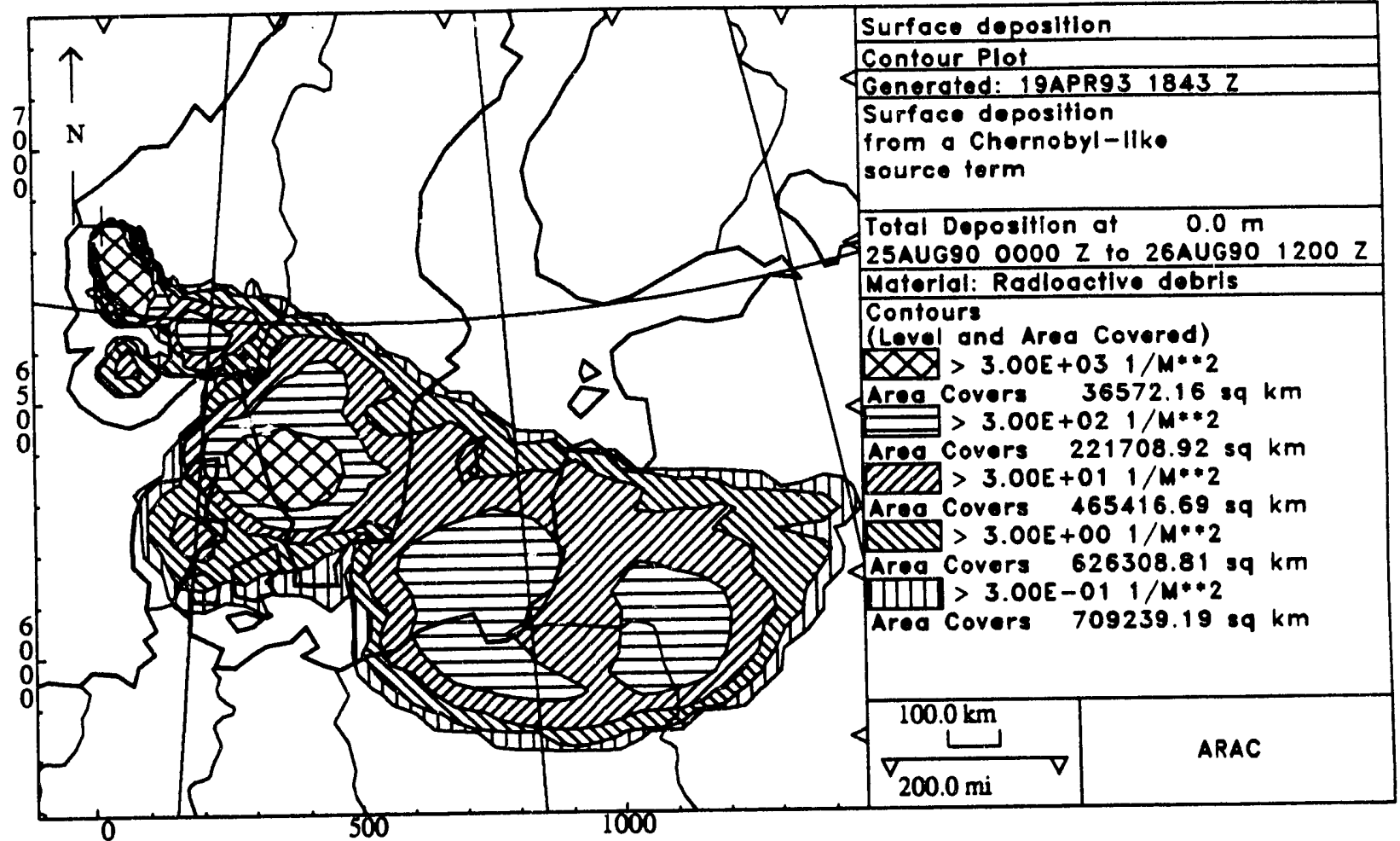

"OLD" MODEL

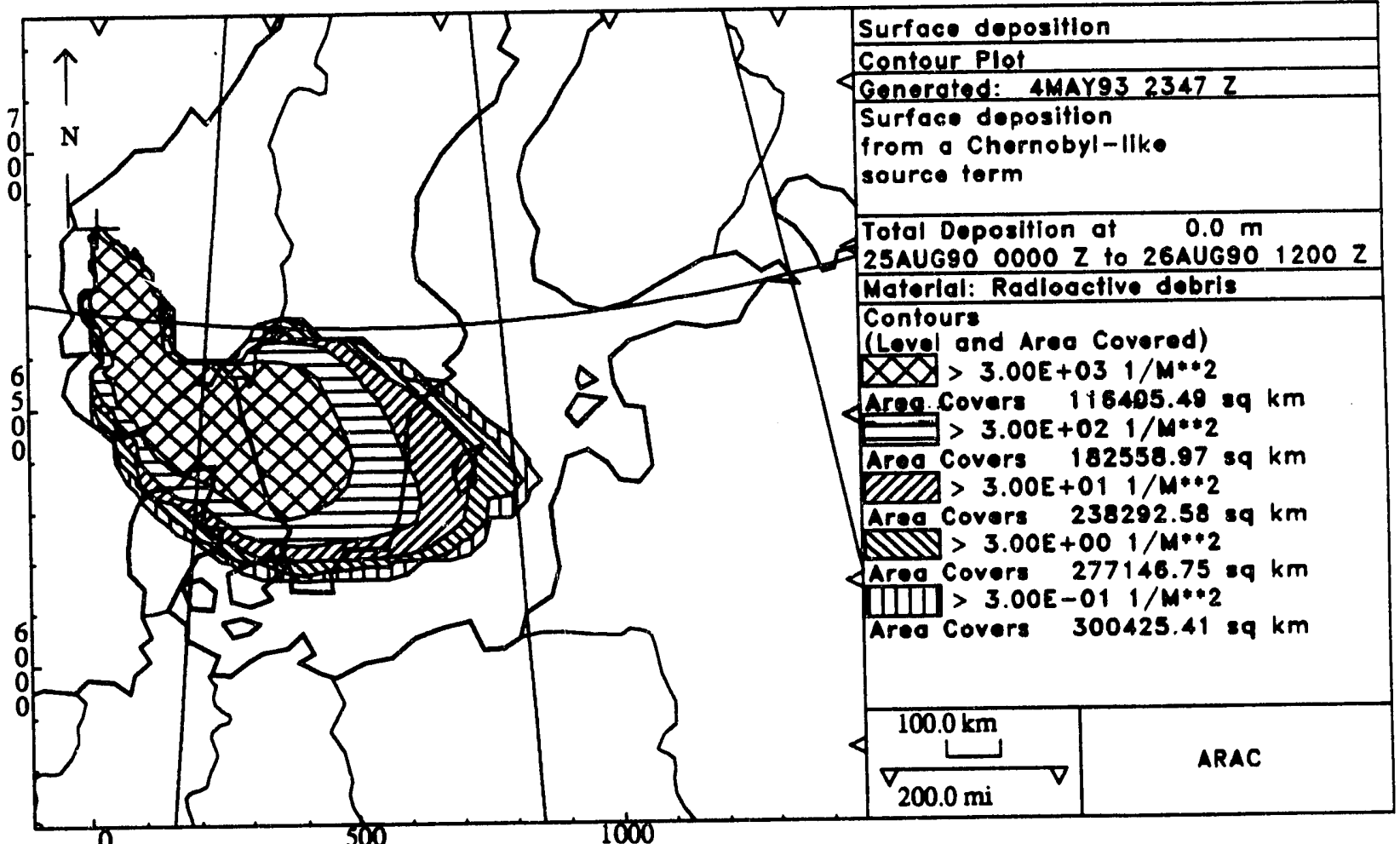

Figure 8. Continuous release. Ground deposition $36 \mathrm{~h}$ after start of release. 


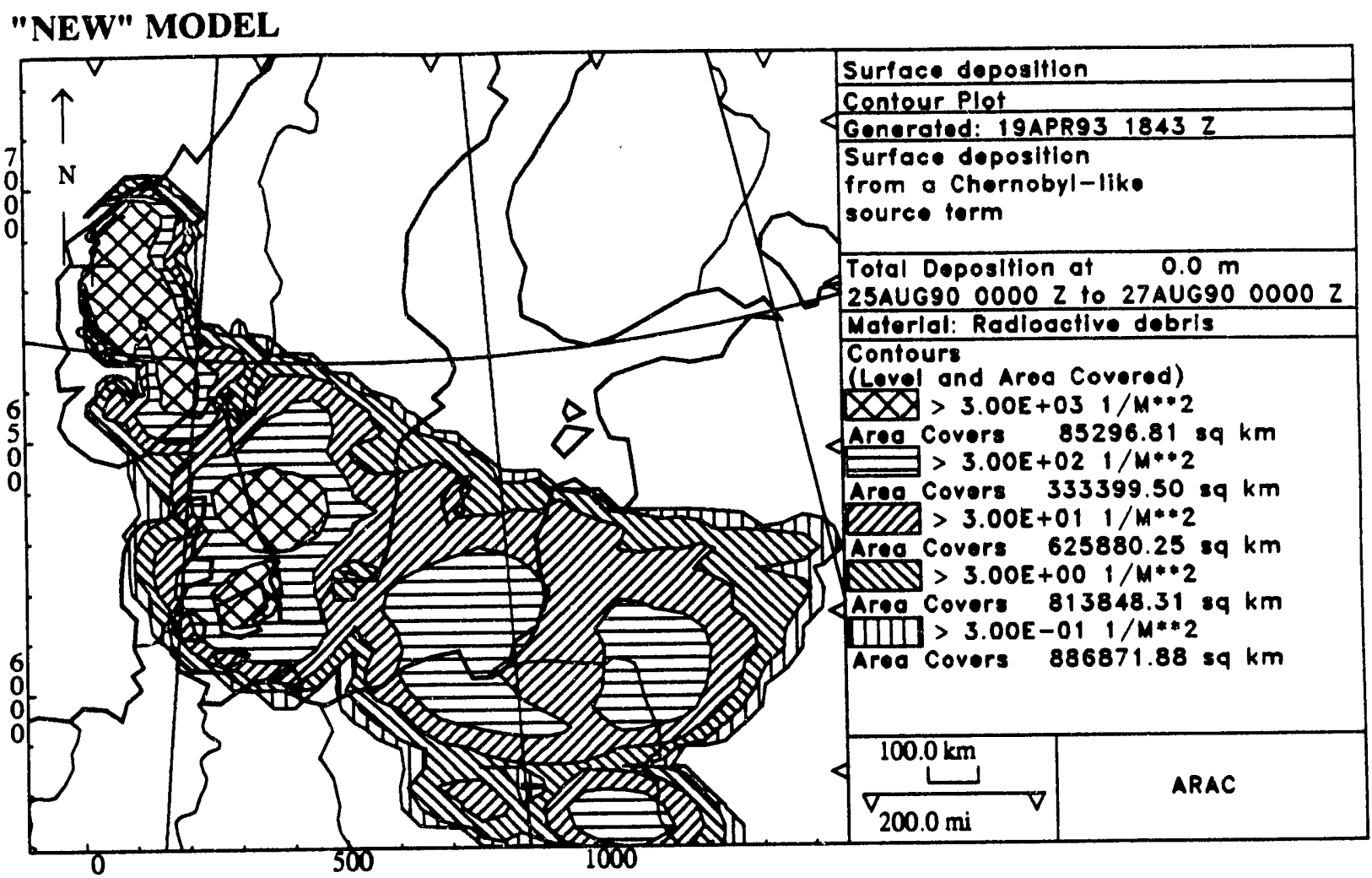

"OLD" MODEL

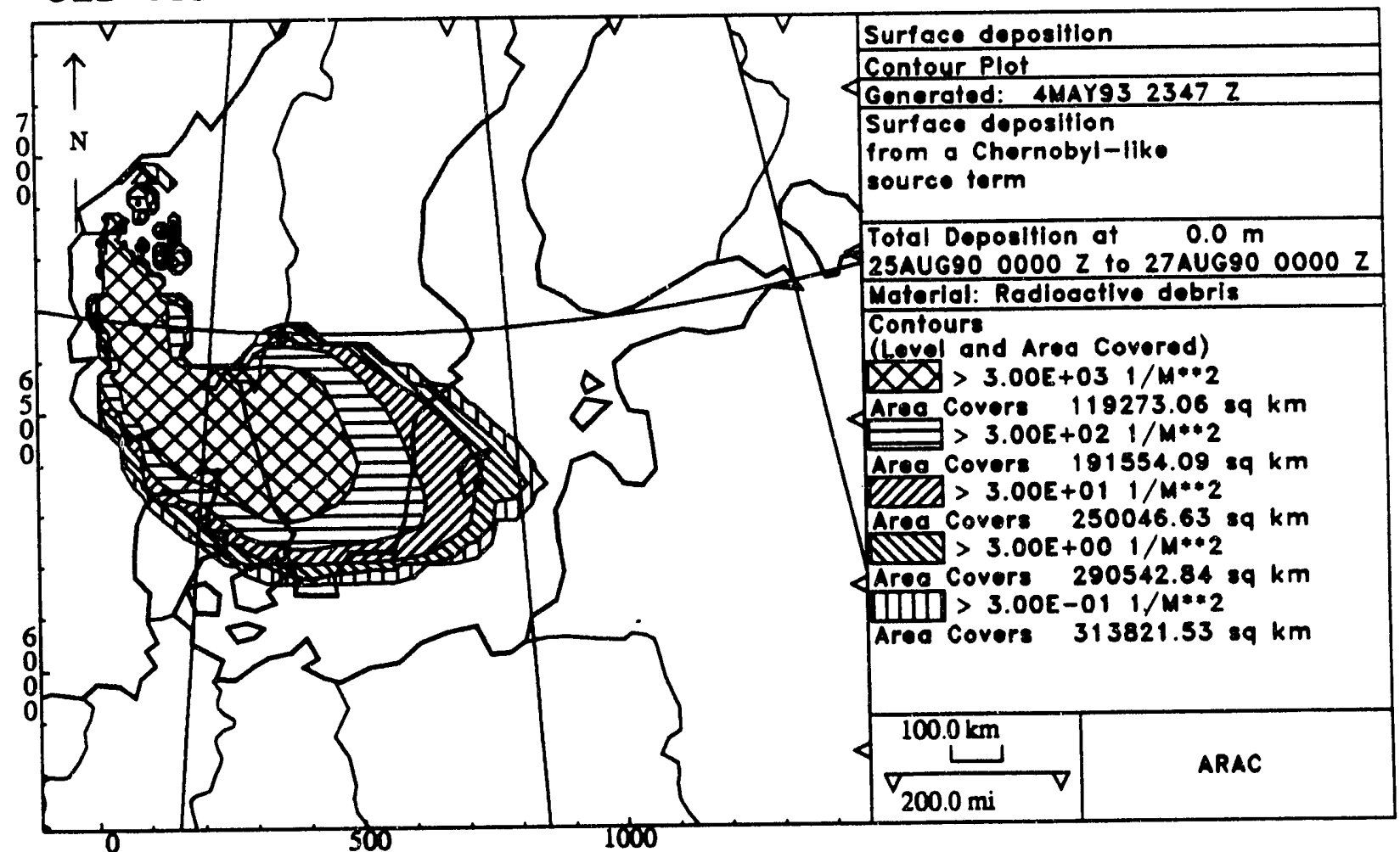

Figure 9. Continuous release. Ground deposition $48 \mathrm{~h}$ after start of release. 


\section{INSTANTANEOUS RELEASE :}

Particles subjected to washout only

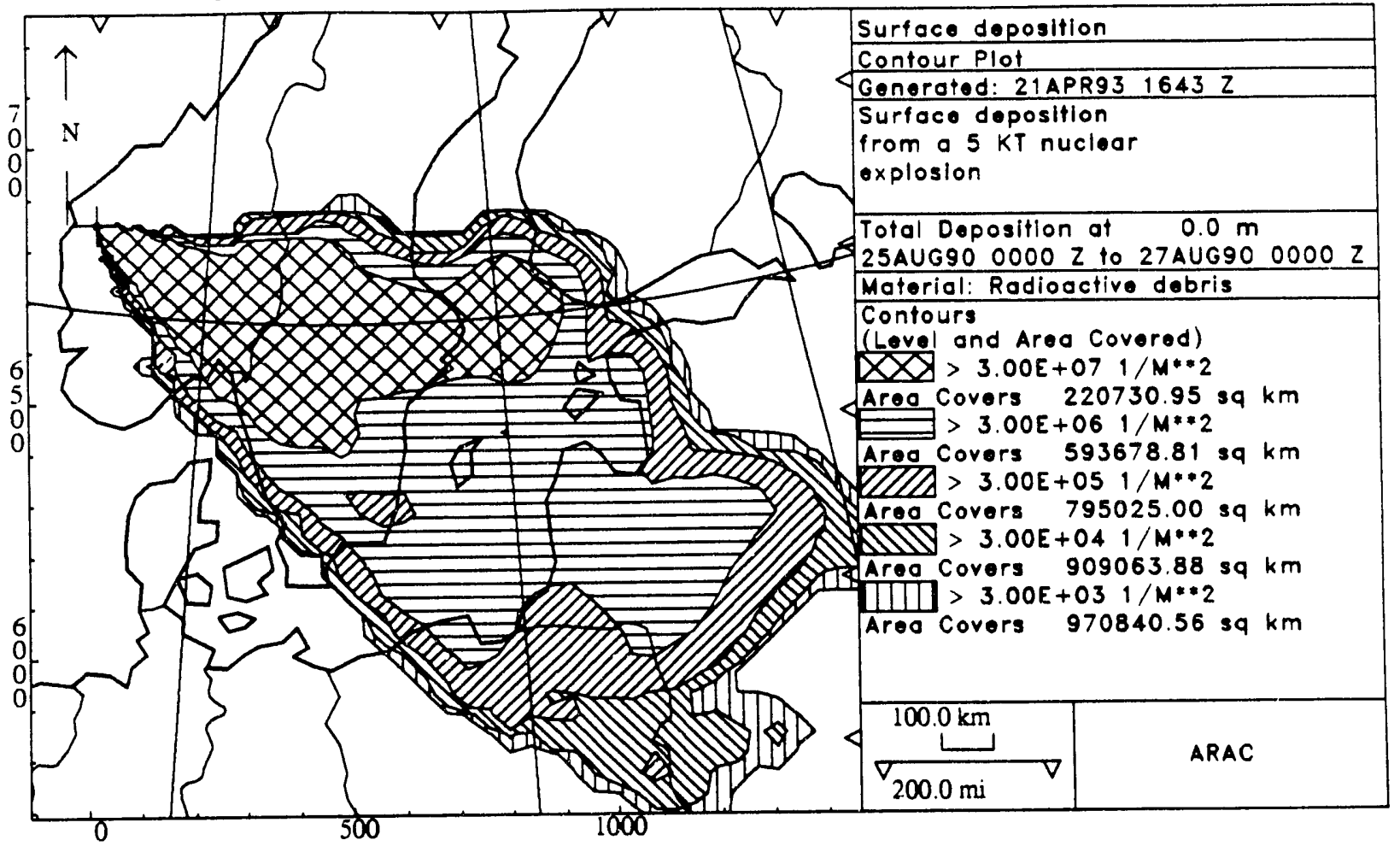

Particles subjected to washout or in-cloud rainout

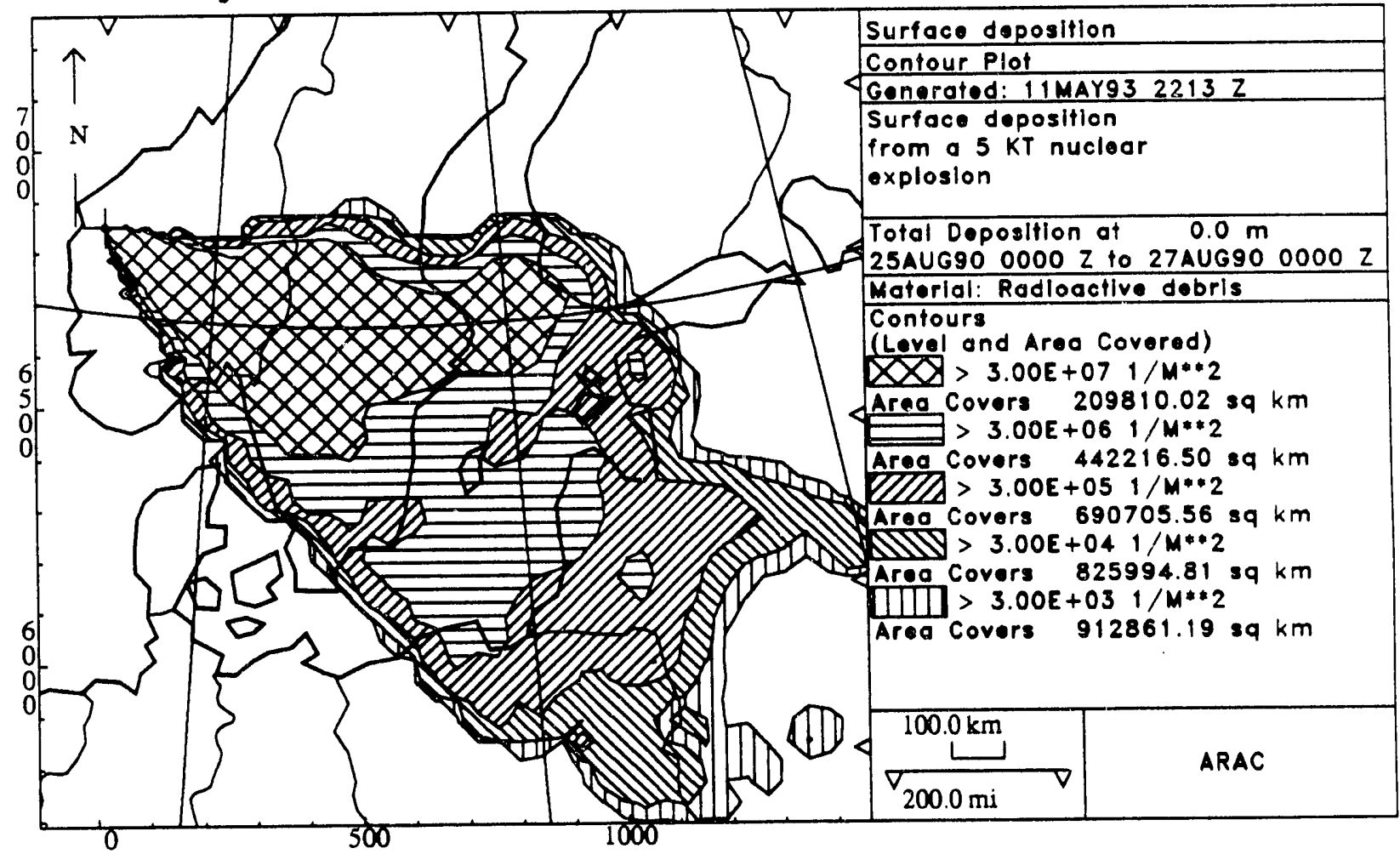

Figure 10. Comparison between pure washout and washout/rainout $48 \mathrm{~h}$ after explosion. 
CONTINUOUS RELEASE :

Particles subjected to washout only

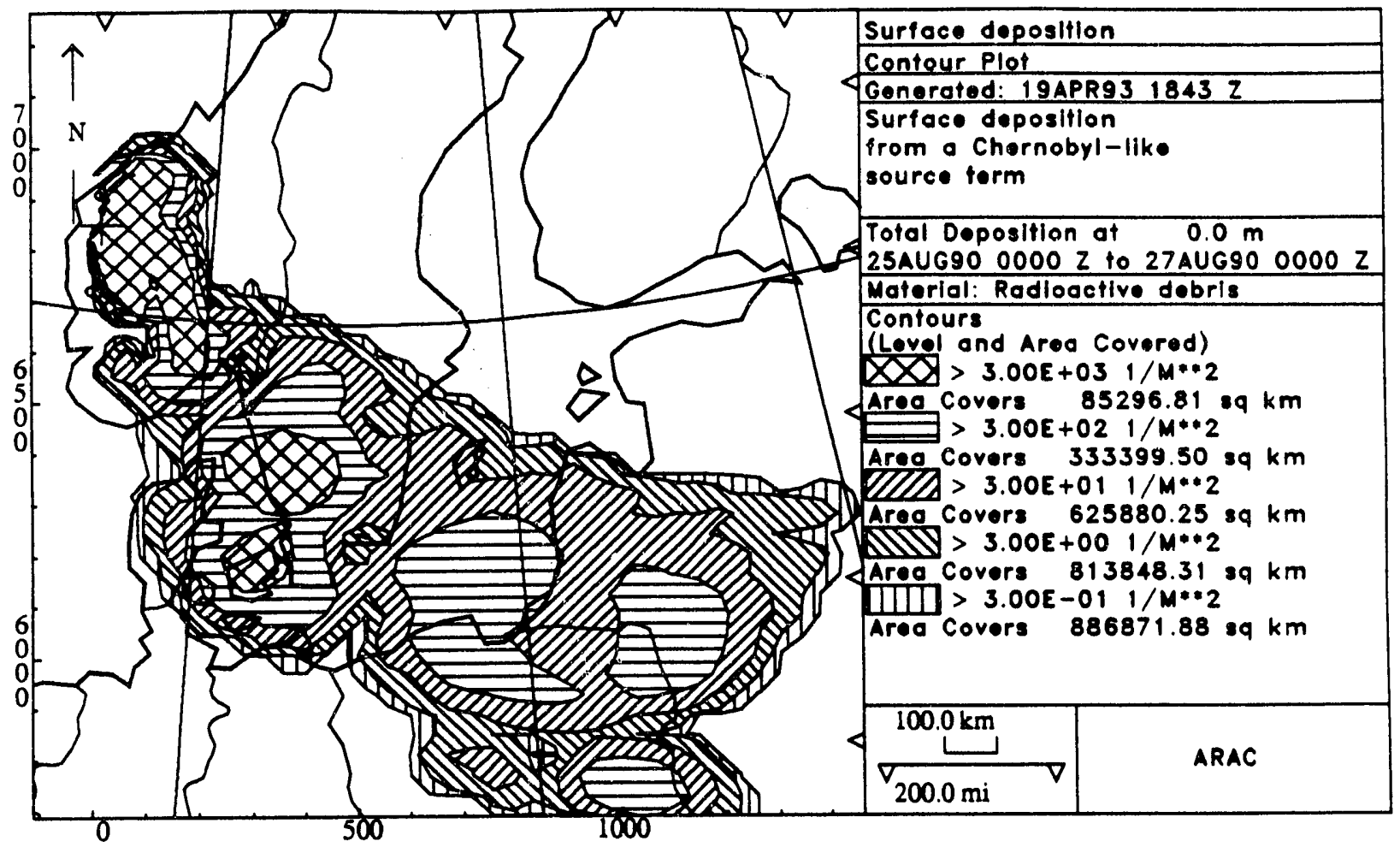

Particles subjected to washout or in-cloud rainout

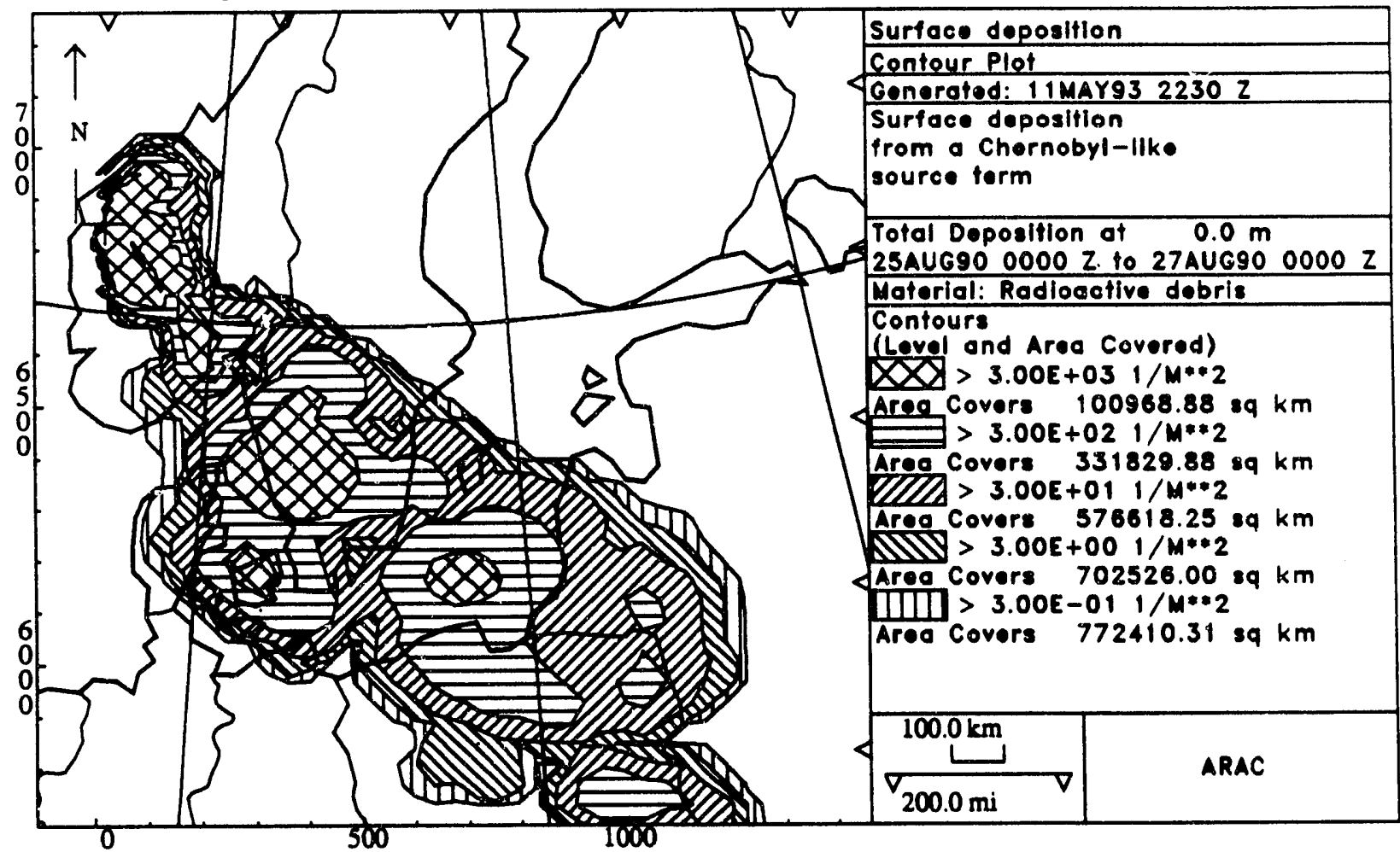

Figure 11. Comparison between pure washout and washout/rainout $48 \mathrm{~h}$ after start of release. 


\section{Discussion and conclusions}

It is, of course, not very surprising that the washout modeling is crucial when long-range transport problems are considered. In a way, the results in this report simply stress that obvious truth.

We think the results emerging from the presented cases clearly show the deficiences of the old models and the questionable quality derived from 'quick judgment' about when, where, and how much it is raining. For instance, Figs. 5 and 6 show a very strange-looking deposition field, since only dry deposition is responsible for the deposition after the washout is turned off. In the old model during the continous release (Figs. 7-9), the dry deposition velocity for the source particles is so low that almost no ground deposition occur after the rain is turned off. One can always argue that the judgement about the washout coefficient was poor, but to enhance the results with the old model a number of runs must be made in an iterative manner.

The difference between pure washout and washout/rainout is interesting (Figs. 10 and 11). In the case of washout/rainout a larger part the radioactivity is deposited at an early stage and the deposition far from the source is actually diminished. This makes sense, since the light particles are those that have the ability to travel a long distance and are more affected by rainout than by washout. The difference, shown in Figs. 10 and 11, is not overwhelming but will need further investigation.

The way the code is presently written the difference in CPU-time for the models can be described by

(OLD ADPIC/NO WASHOUT) : (OLD ADPIC/WASHOUT) : (NEW ADPIC)
1.0
1.7
1.9

In the old model no call to the WASHOUT-subroutine is made when the washout is turned off. This means that the figure for (OLD ADPIC/WASHOUT), in practice, is somewhere between 1.0 and 1.7 depending on how much of the time the washout coefficient is on. In the new model there is always a call to WASHOUT.

It should be noted that it is straightforward to add other arrays. In the new model provision is made for reading a temperature array that could be used for various purposes (is it raining or snowing? feedback to turbulence/bouyance modeling, etc.). This array, however, is not used in the present simulations. 


\section{Acknowledgments}

Many thanks to the following people for their contribution in making this report: Hoyt Walker, John Nasstrom, Rolf Lange, Bryan Lawver, Connee Foster and Lennart Thaning.

This work was performed under the auspices of the U.S. Department of Energy at Lawrence Livermore National Laboraty under contract number W-7405-Eng-48.

\section{References}

Crandall, W. K., C. R. Molenkamp, A. L. Williams, M. M. Fulk, R. Lange and J. B. Knox, :1973, 'An Investigation of Scavenging of Radioactivity from Nuclear Debris Clouds: Research in Progress,' UCRL-51328 Rev. 1, Lawrence Livermore National Laboratory. 


\section{Appendix A: Sample WINDY file}

The 5 th column in the UPR-record is the rainrate $(\mathrm{mm} / \mathrm{h})$. The 6 th column, which is not used, is a temperature flag (above or below frezzing). This column could be used for the temperature field itself.

$$
\begin{array}{llll}
\text { NTIME }=0000 & \text { NRUN }=1 & \text { NDATE }=900825 & \text { AVTIME }=50 . \\
\text { SRH }=0.4 & \text { PWRSL }=.25 & \text { PWRBL }=1 . & \text { TOPSL }=25 \\
\text { TOPBL }=300 . & \text { TOPMI }=500 . & \text { REF }=10 . & \text { SMOLI }=0.0 \\
\text { ISTAB }=4 & & & \\
\text { UPR }= & & &
\end{array}
$$

\begin{tabular}{lllllll}
\hline 'S058_016' & 65.3 & 220. & 1.4 & -1. & 27.5 & 0.0 \\
& 230.7 & 245. & 2.4 & -1. & 27.5 & 0.0 \\
550.0 & 259. & 3.6 & -1. & 26.9 & 0.0 \\
1049.1 & 268. & 5.3 & -1. & 24.1 & 0.0 \\
1739.1 & 273. & 8.1 & -1. & 17.9 & 0.0 \\
2623.0 & 279. & 12.6 & -1. & 9.3 & 0.0 \\
3698.3 & 285. & 17.3 & -1. & 2.4 & 1.0 \\
4956.1 & 288. & 20.0 & -1. & 0.0 & 1.0 \\
6382.4 & 287. & 21.7 & -1. & 0.0 & 1.0 \\
7958.6 & 283. & 22.9 & -1. & 0.0 & 1.0 \\
9658.0 & 284. & 20.9 & -1. & 0.0 & 1.0 \\
11448.3 & 284. & 17.5 & -1. & 0.0 & 1.0 \\
13311.6 & 290. & 20.7 & -1. & 0.0 & 1.0 \\
15291.3 & 289. & 19.7 & -1. & 0.0 & 1.0 \\
17390.4 & 289. & 13.9 & -1. & 0.0 & 1.0 \\
19624.9 & 304. & 10.0 & -1. & 0.0 & 1.0 \\
22330.7 & 301. & 6.0 & -1. & 0.0 & 1.0 \\
26852.3 & 315. & 2.6 & -1. & 0.0 & 1.0 \\
& 31503.4 & 58. & 3.3 & -1. & 0.0 & 1.0
\end{tabular}




\section{Appendix B: Changes in MEDIC- Listing of subroutines and cliches}

New subroutines:

\begin{tabular}{|c|c|c|}
\hline CREATEPRECIP. FOR & - & Creates the PREC.nnn files. \\
\hline NAMEPRECIP.FOR & - & Names the PREC.nnn files. \\
\hline WRITE_PRECIP.FOR & - & $\begin{array}{l}\text { Changes dimension from MEDIC to ADPIC- } \\
\text { dimension and writes out the rainrate array to } \\
\text { PREC.nnn. }\end{array}$ \\
\hline CLOSE_PRECIP.FOR & - & Closes PREC.nnn. \\
\hline PREP_INT.FOR & - & Does the interpolation. \\
\hline
\end{tabular}

New cliches:

WINDYPRECIP. CLI - $\quad$ Contains both the MEDIC-dimensioned and ADPICdimensioned rainrate arrays.

The only new coding is above, but there are also minor changes in a number of subroutines and cliches. Some of these changes are associated with changes in the old NAMELIST-reading. Since the restructured ADPIC will soon be available without the old NAMELIST, these changes are of little interest.

A complete 'new' MEDIC sourcecode, that also takes a maximum of 600 upperair records instead of 15, can be found in a directory that existed May 10, 1993:

DSK\$BACKUP : [MODEL . HH . MEDIC]

with associated cliche-subdirectory.

Furthermore the COM- files that produce an executable file are;

\begin{tabular}{|c|c|c|}
\hline COPY600.COM & - & Copies the necessary subroutines to one file. \\
\hline FOR600.COM & - & $\begin{array}{l}\text { Set up symbols necessary to compile with the } \\
\text { right include files; Compile. }\end{array}$ \\
\hline LINK 600.COM & - & $\begin{array}{l}\text { Produces an executable image, } \\
\text { "MEDIC600.EXE" - A working } \\
\text { MEDIC } 600 . E X E \text { can be found under the above } \\
\text { directory. }\end{array}$ \\
\hline
\end{tabular}




\section{Appendix C}

The constants associated with equation 1 :

$a_{1}=2.700 \mathrm{e}-4, a_{2}=-3.618 \mathrm{e}-6$

$b_{0}=-0.1483, b_{1}=322013.3, b_{2}=-3.00626 \mathrm{e} 10, b_{3}=9.34458 \mathrm{e} 14$

Below is the listing from subroutine WASHOUT. If $\mathrm{c}^{* * *}$ is taken away, it is the version with both rainout and washout.

The function GET_FIELD does the interpolation of the rainrate to the particle position. It also does an optional test whether the particle is within a cloud. In that case it returns in_cloud $=$. true.

Listing from SUBROUTINE WASHOUT:

c..........

C Calculate the rainrate at the particle position...

rain $r=$ get_field $(p x(n), p y(n), p z(n)$, rainpic, in_cloud)

c Translate rainrate into washout coefficient (rainrate in $\mathrm{mm} / \mathrm{h}$ )...

$c$ the polynom-functions tries to (and they do) resemble curves from

c Crandall et.al. (1973) that translates rainrate to washout coefficient.

c If the particle is inside a cloud (in_cloud = .true.) it is subjected

$c$ to rainout instead of washout...

$c$

$c^{\star \star \star}$ if (in_cloud) then

$c * \star$ qlam_e $=2.700 e-4 *$ rainr

$c^{\star \star \star} 1-3.618358 e-6 *$ rainr $* \star 2$.

$C^{\star \star \star}$ else

$\mathrm{C}$

c Here comes the translation to washout coefficient...

$$
\begin{aligned}
& \text { if (ps }(n) \cdot g t .1 \cdot e-5) \text { then } \\
& \text { qlam_e }=2.700 e-4 * \text { rainr - }
\end{aligned}
$$

1

3. $618358 e-6 *$ rainr ${ }^{\star} \star 2$.

else if (ps $(n) .1 t .0 .05 e-5)$ then

qlam_e $=0.0$

else

qlamcoef =

$2.700 e-4 *$ rainr -

1

$$
\text { qlam_e = }
$$$$
3.618358 e-6 * \text { rainr } * * 2 \text {. }
$$

1

$(-0.14833+$

$322013.3^{*} \mathrm{ps}(n)-$

1

3.00626 e10*ps $(n) \star * 2$. +

1

9.334458 e14*ps $(n) * \star 3) *$.$q lamcoef$

endif

$C^{\star \star \star}$ endif

C Now the old coding continues...

$D P M=P P(N) \star\left(1 .-\operatorname{EXP}\left(-Q L A M \_E * D E L T\right)\right)$ 

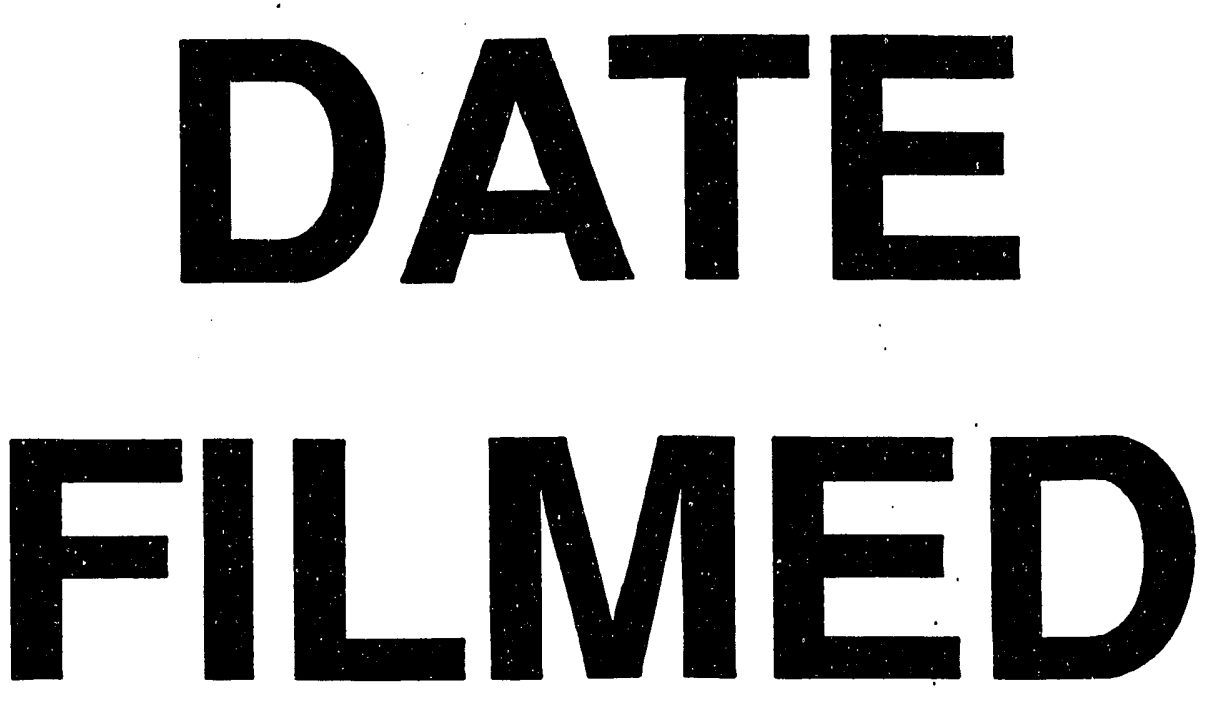

$9 / 28 / 93$
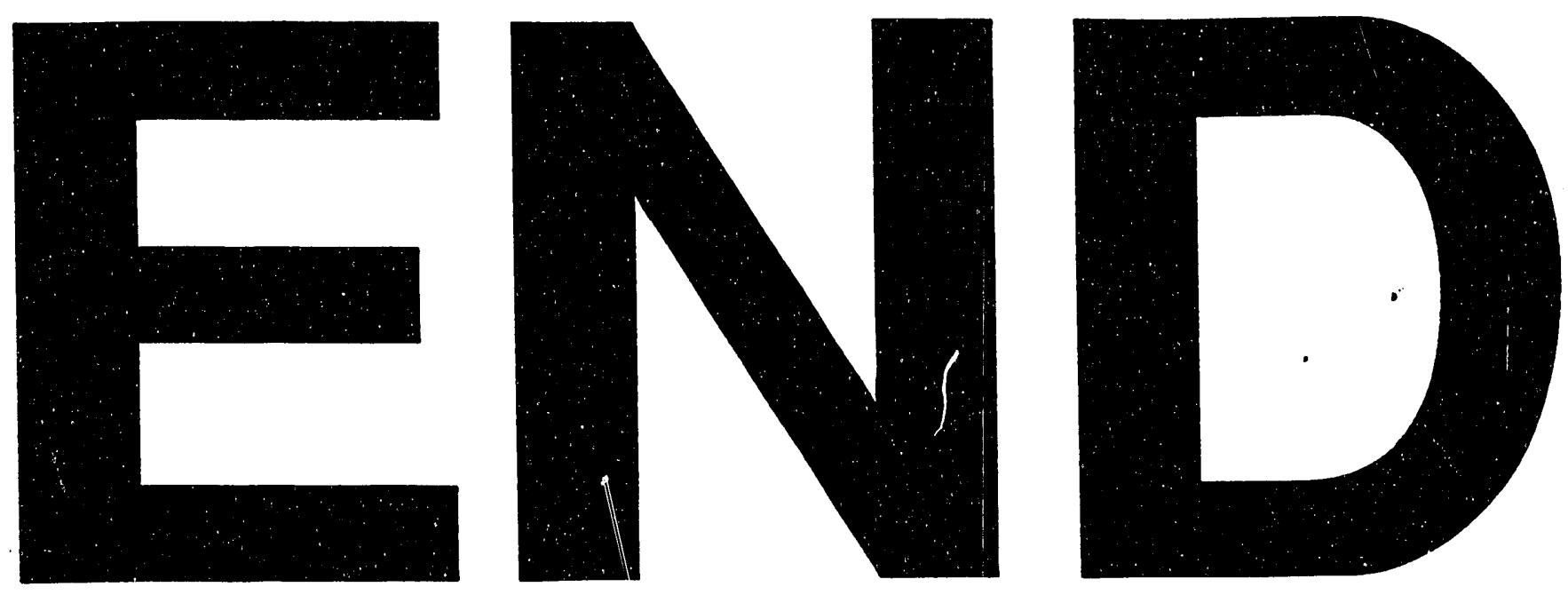
